\title{
Virtual Reality as a Learning Tool in a Group of UNAM Dentistry Students
}

ISSN: 2637-7764

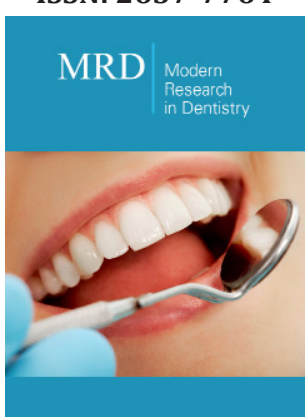

*Corresponding author: Laura Mendoza Oropeza, Professor of Orthodontics, Faculty of Dentistry, UNAM, Mexico

Submission: 䣬 November 26, 2020

Published: 想December 16, 2020

Volume 5 - Issue 5

How to cite this article: Laura Mendoza Oropeza, Virtual Reality as a Learning Tool in a Group of UNAM Dentistry Students. Mod Res Dent. 5(5). MRD. 000625. 2020. DOI: 10.31031/MRD.2020.05.000625

Copyright@ Laura Mendoza Oropeza This article is distributed under the terms of the Creative Commons Attribution 4.0 International License, which permits unrestricted use and redistribution provided that the original author and source are credited.
Laura Mendoza Oropeza*

Professor of Orthodontics, Faculty of Dentistry, UNAM, Mexico

\section{Abstract}

In recent years, has sought to develop and use the Virtual Realitythird dimension as a teaching-learning tool to strengthen student learning. Virtual Reality (RV) in the teaching of the Dentistry degree has consisted of creating 3D models, as well as three-dimensional stereoscopic images and videos of different subjects; This is achieved through two images with different perspectives that reach each of our eyes so that they can be visualized through special lenses, allowing the student to integrate them into a single 3D image with depth.

The objective of the study is to know the benefit of this tool in the learning process of the students. The study was carried out in a group of 4th year of the degree of Dentist Surgeon of the Faculty of Dentistry of the UNAM, it was divided in two groups; one was given the class in a traditional way, while the other was through stereoscopic images and videos in 3D, later they were given a questionnaire to let us know about the learning. The results that were observed was that the 3D group obtained a higher score compared to the traditional teaching group.

Therefore, it can be concluded that the use of Virtual Reality in teaching allows for greater retention of concepts. In addition, it is an intuitive technology in terms of its use since it facilitates the explanation of complex or abstract concepts.

Keywords: Virtual Reality;Learning; 3D; Dentistry students

\section{Introduction}

Virtual reality provides new forms and methods of visualization, engaging the strengths of visual representations that allow learning, especially in students who learn through the sense of sight (visual learning) [1].

At present virtual reality encompasses a set of technologies related to each other, among these technologies are 3D models that, from a technical point of view, is a set of geometries representing an "object" in three dimensions, ie: width, length and depth [2]. These models allow to be rotated and observed from any point of view. 3D models can be used in conjunction with various visualization technologies, such as:

1) Immersive virtual reality: a three-dimensional environment is created by a computer and can be manipulated through the use of helmets, gloves or other devices (oculus) [3] that capture the position and rotation of different parts of the human body (Figure 1); It is currently used for 3D environments as a support tool in academic activities, for teachinglearning at the UNAM (IXTLI room) [4,5].

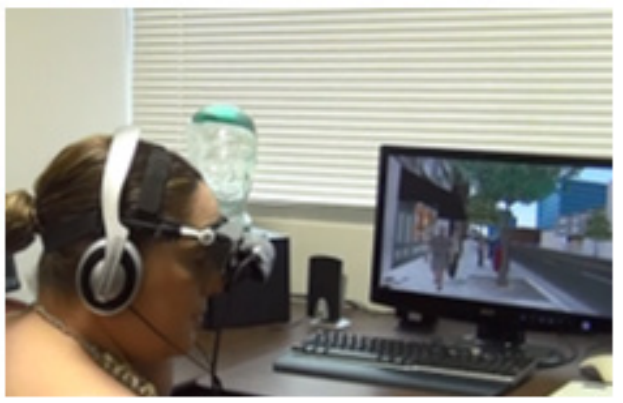

Figure 1: Immersive virtual reality. 
2) The non-immersive: augmented reality and 3D created from stereoscopic images and videos, in which it is possible to interact in real time with different people, spaces and environments from a distance, without the use of additional devices on the computer; one of the advantages is that it requires fewer resources to generate it, such as the one used in the Faculty of Dentistry (Margarita Chorné y Salazar room). This technology is applied in various subjects such as Orthodontics (Preventive and Interceptive), Human and Dental Anatomy, Oral Health Education, Preventive Dentistry, Oral Public Health, Occlusion, Anesthesia, Endodontics and Maxillofacial Surgery, using special attachments such as lenses (Figure 2) [6].

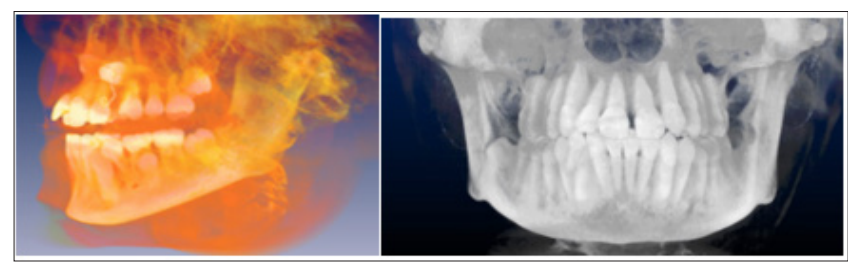

Figure 2: 3D volumetric representation.

Stereoscopy takes advantage of human binocular vision. The brain receives two different images (representing the angle of view of each eye) and analyzes them. Subsequently, the brain generates in the viewer's senses a sensation of immersion within different scenarios of a reality-generated by a computer - in which the relief and depth within a three-dimensional world can be perceived [7].

The objective of this study is to compare the learning outcome of a $4^{\text {th }}$ year group of students, using virtual reality didactic materials such as 3D images and stereoscopic videos based on the contents of the 4th year Orthodontic unit program of the degree of Dentist Surgeon taught by the Faculty of Dentistry (FD) of the National Autonomous University of Mexico (UNAM).

The Virtual Reality didactic material used in the 3D room, is elaborated with the aim to educate the student by facilitating learning through the simulation of reality. A disadvantage of this tool is the high costs involved (computers, scanners, cameras, software programs); however, this technique reduces clinical risk during student-patient training (Figure 3) [8].

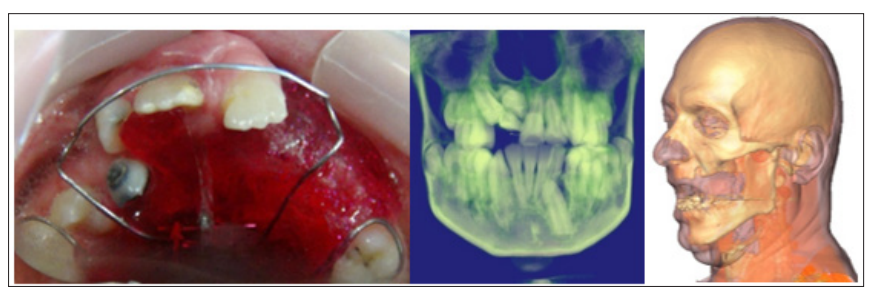

Figure 3: Cleft palate, anteroposterior view of a skull and model of a toothless patient with an open mouth.

\section{Material and Methods}

A prospective cross-sectional study was carried out in 35 $4^{\text {th }}$ year students of the Dental Surgeon degree of the FD, UNAM who took the Orthodontics subject. Traditional teaching was compared with teaching through virtual reality as a learning tool. It was evaluated by means of a questionnaire, which contained the questions related to the topic, previously validated by a group of experts applying before (pre-test) and after (post-test) teaching the class in a traditional way and in 3D [8-10].

The students were divided into two groups for their study in a random way: 18 for the traditional group and 17 for the VR group. The data obtained was processed with the SSPP 20 software. The results obtained in terms of gender distribution were: 23 women and 12 men with an average age of: 12 of 21, 11 of 22, 10 of 23 and 2 of 24 (Graph 1).

\begin{tabular}{|c|c|}
\hline 21 & 000000000000 \\
\hline 22 & 00000000000 \\
\hline 23 & 0000000000 \\
\hline 24 & 00 \\
\hline
\end{tabular}

Graph 1: Age distribution of the students.

The average obtained by the traditional method was: $4.62+/-$ 0.9141 , Me 4.34 with $95.46 \%$ confidence (before) and an average of $6.64+/-1.2413$, Me 6.665 with $93.83 \%$ confidence (after) for the 18 students who formed that group (Table 1).

Table 1: Learning outcomes by the traditional method.

\begin{tabular}{|c|c|c|}
\hline Measures & Before & After \\
\hline Mean & 4.623333 & 6.6422 \\
\hline Median & 4.34 & 6.665 \\
\hline Mode & 4.1 & 6.25 \\
\hline SD & 0.914163 & 1.241354 \\
\hline Variance & 0.835694 & 1.540959 \\
\hline Kurtosis & -0.69853 & -0.84193 \\
\hline Skenosis & 0.444333 & -0.34667 \\
\hline Range & 3 & 4.17 \\
\hline Min & 3.25 & 4.58 \\
\hline Max & 6.25 & 8.75 \\
\hline No. of Students & 18 & 18 \\
\hline Confidence level (95\%) & 0.454603 & 0.617311 \\
\hline
\end{tabular}

A linear regression was carried out to know the learning outcome before and after the traditional teaching. In graph 2 , it is observed that most of the scores are not close to the line in the preand post-of traditional teaching. 


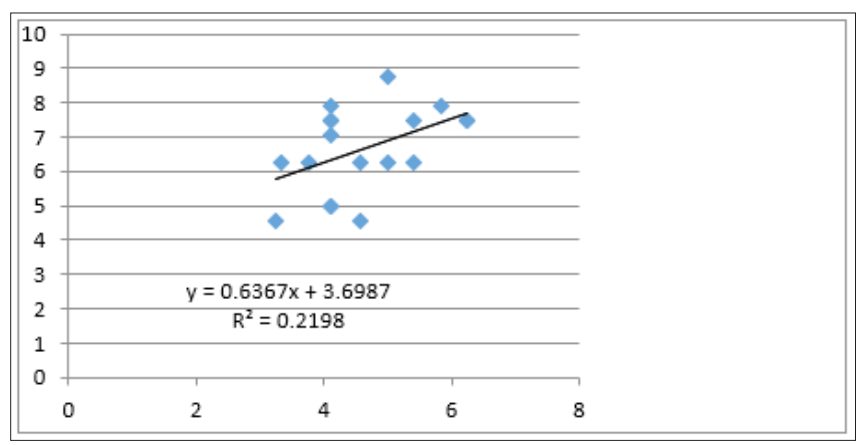

Graph 2: Linear coefficient of learning outcome through the traditional method.

According to the formula where the dependent variable $Y$ (result after teaching) the following scores were obtained: $\mathrm{Y}=0.6367 \mathrm{x}+3.6987$ with $\mathrm{R} 2=0.2198$; interpreting: the learning outcome did not turn out to be significant after teaching in the traditional way.

Table 2: Learning outcomes with the use of VR.

\begin{tabular}{|c|c|c|}
\hline Measures & Before & After \\
\hline Mean & 4.768824 & 7.52 \\
\hline Median & 4.58 & 7.91 \\
\hline Mode & 4.58 & 7.91 \\
\hline SD & 0.827344 & 0.711539 \\
\hline Variance & 0.684499 & 0.506288 \\
\hline Kurtosis & -0.7986 & -0.4645 \\
\hline Skenosis & 0.089663 & -0.94458 \\
\hline Range & 2.92 & 2.08 \\
\hline Min & 3.33 & 6.25 \\
\hline Max & 6.25 & 8.33 \\
\hline No. of Students & 17 & 17 \\
\hline Confidence level (95\%) & 0.425381 & 0.36584 \\
\hline
\end{tabular}

The learning results of the students using VR (Table 2) were as follows: the mean obtained before teaching the class was 4.7+/-DS 0.827344, Me 4.58, Mo 4.1, while the mean after of teaching in VR, was: $7.52+/-0.711539$, Me 7.91. Mo 6.25 for a $96.35 \%$ confidence level applied to 17 students.

In the linear regression using Virtual Reality, it was found that $y=0.105 x+7.0191$ with an $R 2$ of 0.0149 in relation to the pre and posttest. In graph 3 , most of the data is close to the line; the column on the left represents the score, showing that almost all the students obtained between 8 and 9 and a few between 6 and 7 out of 10; inferring that the learning outcome of the students who took the class through virtual reality was significant, since the majority obtained an improvement in their grade.

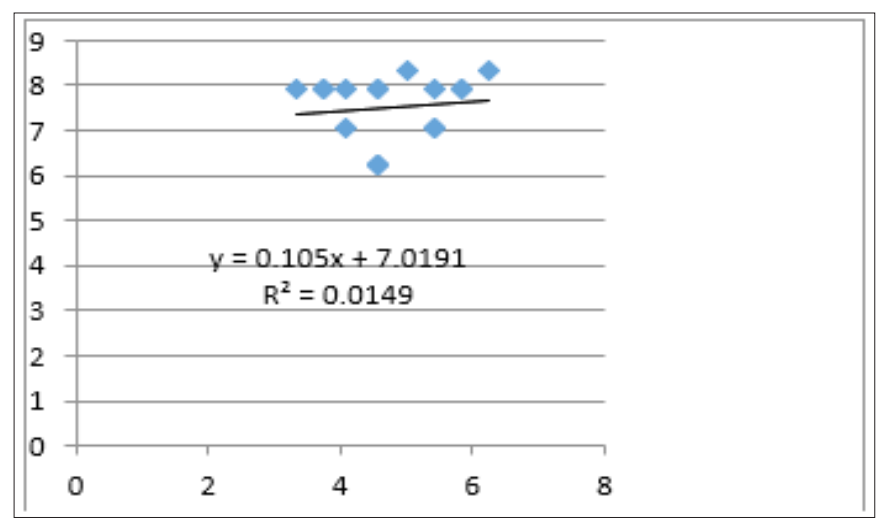

Graph 3: Virtual Reality (VR) learning outcome linear coefficient.

\section{Discussion}

One of the challenges of this tool is that the material must be created in 3D, so it is necessary to have specialized teachers, specialized equipment for its capture and reproduction (3D room, computer with great capacity for capture and reproduction).

It is important to mention that, in the first application of the questionnaire, the two study groups obtained almost the same scores (the same prior knowledge); however, in the second application the Virtual Reality (VR) group achieved a higher score.

These tools establish the link between written language and visual language that favors the learning of complex and abstract knowledge, necessary in theoretical and theoretical-practical subjects, as well as helping to synaptically relate the contents of all subjects.

Human beings can more easily recognize 3D objects than 2D because the greater detail that 3D objects present, especially indepth signals, 2D requires more time to process the information, $3 \mathrm{D}$ vision is considered more intuitive $[11,12]$.

Of course, we should never lose sight of the fact that the use of technology is only a didactic resource used by teachers to better train students in the construction of their knowledge.

Issenberg and Stefanidis mention in their studies that simulation-based education provides a learning environment in which the technical skills acquired are transferable to clinical practice $[13,14]$.

For most students the Virtual Reality strengthened prior knowledge, and also helped to clarify the doubts, because they were allowed to observe the bony structures in the three dimensions of space and better understand the relationship of them without having to imagine. In this sense, Walters and Stefanidis point out that this learning is maintained over time $[15,16]$. However, it has been observed that people with visual disabilities (use of magnifying glasses) find it difficult to visualize stereoscopic images, which is why it is necessary to reinforce the auditory support of the visual contents. 


\section{Conclusion}

The use of this technology for the Dentistry training in the Faculty of Dentistry allows the teacher to instruct dental procedures to the whole group at the same time, since in general many of these procedures are performed individually on the patient, not allowing the other participants to observe and learn simultaneously due to the size of the oral cavity.

Virtual Reality helps students to process stereoscopic images and videos with three-dimensional (3D) space perception that any other graphic representation system lacks. Furthermore, it is a fairly intuitive technology in terms of its use; likewise, it facilitates the explanation of complex or abstract concepts. On the other hand, the use of Virtual Reality mechanisms implies an added motivation for the student since it encourages him to learn in a realistic and safe way and to continue exploring the real world.

\section{References}

1. Pantelidis VS (2009) Reasons to use virtual reality in education and training courses and a model to determine when to use virtual reality. Themes in Science and Technology Education pp. 59-70.

2. Golzarri A, Ortiz R (2006) La tecnología informática y sus aplicaciones para la odontología. Revista Odontológica Mexicana 10(3): 138-142.

3. Oculus Rift (2016) https://www.oculus.com.

4. Castro Lechtaler Antonio BCFMLC. Simulación inmersiva con realidad aumentada. Escuela superior Teórica Facultad de Ingeniería.

5. Antonio CL, Federico BC, Matias C, Alejandro K, Alexis P (2014) Simulación inmersiva con RealidaD Aumentada. Argentina.

6. Julio C, Julio B (2016) Posibilidades educativas de la realida aumentada. New Approaches in Educational Research 5(1): 46-52.
7. Hibbard P, Haines AE, Hornsey RL (2017) Magnitude, precision, and realism of depth perception in stereoscopic vision. Cognitive Research: Principles and Implications 2(1): 25.

8. Persky S, Kaphingst KA, McCall C, Lachanc C, Beall AC, et al. (2009) Presence relates to distinct outcomes in two virtual environments employing different learning modalities. Cyberpsychol Behav 12(3): 263-268.

9. Vincent DS, Sherstyuk A, Burgess L, Connolly KK (2008) Teaching mass casuality triage using skills immersive three-dimensional virtual reality. Acad Emerg Med 15(11): 1160-1165.

10. Gómez AR, Paez JA, Cortes JA, González Bernal MA (2015) Aplicación de la realidad aumentada a los procedimientos ortodónticos. Universidad Francisco José de Caldes. Redes de Ingeniería. 6: 77-88.

11. Blavier A, Gaudissart Q Cadière GB, Nyssen AS (2006) Impact of 2D and 3D Vision on performance of novice subjets usibg da Vinci robotic system. Acta Chir Belg 106(6): 662-664.

12. Jafar M, Chun Lam M (2017) Stereoscopic vision movile augmented reality system Architecture in assembly tasks. Journal of Engineering and Applied Sciences 12(8): 2098-2105.

13. Issenberg SB, McGaghie WC, Petrusa ER, Lee Goordon D, Scalese RJ (2005) Features and uses of high-fidelity medial simulations trat lead to effective learning: a BEME systematic review. Med Teach 27(1): 10-28.

14. Stefanidis D, Sevdalis N, Paige J, Zevin B, Aggarwal R, et al. (2015) Simulation in surgery: what's needed next? Ann Surg 261(5): 846-853.

15. Waters PS, McVeigh T, Kelly BD, Flaherty GT, Devitt D, et al. (2014) The acquisition and retention of urinary catheterisation skills using surgical simulator devices: teaching metho or student traits. BMC Med Educ 14: 264.

16. Stefanidis D, Korndorffer JR Jr, Sierra R, Touchard C, Dunne JB, et al. (2005) Skill retention following proficiency-based laparocopic sumulator trainin. Surgery 138(2): 165-170. 